\title{
Erratum to: Decadal variation of surface solar radiation in the Tibetan Plateau from observations, reanalysis and model simulations
}

\author{
Qinglong You • Arturo Sanchez-Lorenzo • \\ Martin Wild • Doris Folini · Klaus Fraedrich • \\ Guoyu Ren $\cdot$ Shichang Kang
}

Published online: 26 July 2012

(C) Springer-Verlag 2012

\section{Erratum to: Clim Dyn \\ DOI 10.1007/s00382-012-1383-3}

In the original publication of this article, the correct citation in the Introduction should read as "On the other hand, the latter study (Tang et al. 2011) suggests that a strong in homogeneity occurred in SSR series at some stations in 1994, assuming that the measurements before these years were more erroneous than afterwards in China".

The online version of the original article can be found under doi:10.1007/s00382-012-1383-3.

Q. You $(\bowtie) \cdot$ S. Kang

Laboratory of Tibetan Environment Changes and Land Surface Processes, Institute of Tibetan Plateau Research, Chinese

Academy of Sciences (CAS), Beijing 100085, China

e-mail: yqingl@126.com

Q. You · K. Fraedrich

Meteorological Institute, University of Hamburg, KlimaCampus, 21044 Hamburg, Germany

Q. You · G. Ren

Laboratory for Climate Studies, National Climate Center, China Meteorological Administration (CMA), Beijing 100081, China

\author{
A. Sanchez-Lorenzo $\cdot$ M. Wild · D. Folini \\ Institute for Atmospheric and Climate Science, ETH Zurich, \\ Zurich, Switzerland \\ e-mail: arturo.sanchez@env.ethz.ch \\ M. Wild \\ e-mail: martin.wild@env.ethz.ch \\ D. Folini \\ e-mail: doris.folini@env.ethz.ch \\ S. Kang \\ State Key Laboratory of Cryospheric Science, Chinese Academy \\ of Sciences (CAS), Lanzhou 730000, China
}

